\title{
Reducing HIV- and TB-Stigma among healthcare co-workers in South Africa: Results of a cluster randomised trial
}

Nina Sommerland, PhD,

Researcher, Centre for Population, Family and Health, Department of Sociology, University of Antwerp, Antwerp, Belgium

Caroline Masquillier, PhD

Senior Researcher, Centre for Population, Family and Health, Department of Sociology, University of Antwerp, Antwerp, Belgium.

Asta Rau, PhD

Senior Researcher, Centre for Health Systems Research and Development, University of the Free

State, Bloemfontein, South Africa.

Michelle Engelbrecht, PhD

Director and Senior Researcher, Centre for Health Systems Research and Development, University of the Free State, Bloemfontein, South Africa

Gladys Kigozi, PhD

Senior Researcher, Centre for Health Systems Research and Development, University of the Free

State, Bloemfontein, South Africa.

Triantafyllos Pliakas, MSc

Research fellow, Centre for evaluation, Department Public Health, Environments and Society, London School of Hygiene and Tropical Medicine, London, United Kingdom

Andre Janse van Rensburg, PhD

Research fellow, Centre for Rural Health, University of KwaZulu-Natal, Durban, South Africa

Edwin Wouters, PhD

Professor, Centre for Population, Family and Health, Department of Sociology, University of Antwerp, Antwerp, Belgium.

*Corresponding author: Nina Sommerland, S.Z.210, 2000 Antwerp, Belgium nina.sommerland@gmail.com. 


\section{Introduction}

In South Africa, human immunodeficiency virus (HIV) and tuberculosis (TB) together make up a deadly co-epidemic. A total of 7.1 million South Africans were living with HIV in 2016 (UNAIDS, 2018). In addition, TB in South Africa has one of the highest prevalence rates in the world (781 per 100,000 in 2016), of which $10.5 \%$ were multi-drug resistant (World Health Organization, 2018). The dual impact of HIV and TB has severe consequences for the South African healthcare workforce, putting additional strain on hospitals that are already experiencing severe understaffing (van Rensburg et al., 2012). The situation has led to South Africa having one of the highest rates of emigration of nurses and physicians to seek work elsewhere (Rispel, 2016; Rispel \& Bruce, 2014).

Healthcare workers (HCWs) are also directly affected by the co-epidemic. For example, HIV equally affects the workforce as the general population: estimates of the HIV prevalence among South African HCWs range from $11.5 \%$ to $20.0 \%$ (Adamsi et al., 2013). Additionally, occupational exposure to TB constitutes a major health risk for HCWs and renders them three times more likely to acquire it as compared to the rest of the population (Baussano et al., 2011; Joshi et al., 2006). TB has also been labelled as an occupational hazard, stressing that HCWs need to have access to care at an immediate distance from where they work (World Health Organization et al., 2011).

Given the devastating consequences of the co-epidemic on the health system, it is vital that HCWs with HIV and/or TB receive care, both for their own health and for the functioning of the health system for which they are indispensable. Consequently, it is critical to search for strategies to improve the access to care for HCWs (de Vries et al., 2011; Nyblade et al., 2009; Nyblade et al., 2019; Uebel et al., 2007; World Health Organization et al., 2011). Previous research has demonstrated that HIV- and TB-related stigma and discrimination not only has a negative impact on the mental health and wellbeing of HCWs, but are important barriers to the delivery of accessible and quality health services (J A Reid et al., 2019; Nyblade et al., 2009, 15; N. Sommerland et al., 2017; Stangl et al., 2019). Notably, Quinn and Chaudoir (2009) explored the consequences of anticipated stigma of PLWH on healthcare visits, which could be a source of great distress and impact care-seeking. The results of previous 
literature reviews by Nyblade et al. (2009) and Nyblade et al. (2019) confirm this as a field that needs priority, but to our knowledge, no intervention has been tested to reduce the stigma directed from HCWs to other colleagues.

Stigma, as originally defined by Erving Goffman, is a process of differentiation and othering that can cause discrimination and modified behaviour for those targeted (Goffman, 1963). Stigma occurs when a certain characteristic is negatively regarded and the person labelled is devalued. Manifestations of stigma can include outward, negative attitudes, perceptions and behaviours (external), but also negative self-perception and internalisation of the tainted identity (internalised) (Edwin Wouters et al., 2016).

Both HIV and TB are illnesses carrying a heavy social stigma and are part of diseases recently conceptualised in encompassing theoretical frameworks on stigma of health and illness (Stangl et al., 2019). People living with HIV are often labelled as outcasts due to the considered 'immoral' practices through which the virus is transmitted (e.g. sexual practices and drug use), its high prevalence in marginalised communities and fear of contagion among the public. TB, an older infectious disease, also invokes stigma and discrimination. Historically, TB patients were demonised and isolated because of fear of their infectivity (Courtwright \& Turner, 2010; Packard, 1989), but the distribution of curative, affordable chemotherapy in the 1960-1970s significantly diminished stigma associated with TB (Sontag, 1989). The increase of multi-drug resistant and extremely drug-resistant TB has increased the fear of infection, which is even more urgent for HCWs as they are more exposed in hospitals and then get associated with these forms of TB (Marais, 2016). However, the co-epidemic, where $60 \%$ of TB cases with a known HIV status are HIV-positive, has renewed suspicions about TB patients (World Health Organization, 2018). The negative effects normally associated with HIV are thus now - in the context of the co-epidemic - being transferred to TB (Daftary, 2012; Engelbrecht et al., 2017).

The stigma surrounding HIV and TB in the healthcare workplace can thus be a contributing force to HCWs avoiding and postponing care, driving up morbidity and mortality (Khan et al., 2015; Siegel et al., 2015). Stigma directed from HCWs towards patients has previously been much explored 
(Donnelly et al., 2016; Kinsler et al., 2007; Wagner et al., 2014; Waluyo et al., 2015), but this study addresses the need to focus on stigma directed from HCWs to other HCWs, within the healthcare workforce. The need to address stigma and discrimination is further emphasised in the South African national strategic plan for HIV, TB and STIs, 2017-2022 (South African National AIDS Council, 2017).

To address the above-cited research gap in the field of stigma reduction interventions, the Centre for Population, Family and Health (CPFH) at the University of Antwerp and Centre for Health Systems Research \& Development (CHSR\&D) at the University of the Free State, jointly conducted a cluster-randomised controlled trial: 'Towards a health-enabling working environment- developing and testing interventions to decrease HIV and TB stigma among HCWs in the Free State, South Africa' (A. Rau et al., 2018). The project aimed to develop and test an HIV- and TB stigma-reduction intervention in four randomly selected public hospitals with four control hospitals in the Free State Province of South Africa. In addition, we were interested in understanding how the intervention worked in relation to stigma and how the study participants had made use of what they may have learned from the intervention.

\section{Methods}

The study employs a mixed-methods approach, combining quantitative and qualitative methods. According to Leech and Onwuegbuzie (2009), the approach falls into the category of partially mixed sequential dominant status design, where quantitative analysis is the dominant analysis because it would measure the outcome of the trial. Methods are applied sequentially with quantitative methods being followed and complemented by qualitative methods. In addition to statistical methods to measure the intervention effect, we also explore, through qualitative focus groups, if, how and why the intervention affected HIV and TB stigma among HCWs in the intervention hospitals (Alicia O'Cathain et al., 2014; A O'Cathain et al., 2013; Sandelowski, 1996). Integration of quantitative and qualitative methods is achieved through the explanatory sequential design, where the qualitative 
research follows on the quantitative research questions and data analysis. Furthermore, the results are integrated as they are published together with both the qualitative and quantitative results to explore similar issues with the intervention (Fetters et al., 2013).

\subsection{Trial}

The trial was cluster-randomised on a hospital-level and had the primary outcome of reducing HIV and TB stigma among HCWs in the intervention hospitals. The study was approved by two independent ethics committees, the University of Antwerp Ethics Committee for the Social Sciences and Humanities (SHW_15_28_03) and the University of the Free State Health Sciences Research Ethics Committee (Institutional Review Board number 6240; clearance reference number ECUFS 55/ 2015).

\subsubsection{Sampling}

\section{Quantitative}

The unit of randomisation was the hospitals in which the participants worked. From each randomised hospital, a selection of HCWs participated in the study. Furthermore, the intervention was also implemented on a hospital level. Out of the 28 public hospitals in the Free State, one was excluded as it had been the study site of the first pilot study (Khan et al., 2015). The remaining 27 hospitals were stratified into three groups based on the number of staff and their geographical districts; the first group included 'large' hospitals, the second 'medium' and the third 'small' hospitals (Figure 1). Two 'large', two 'medium' and four 'small' hospitals were drawn from these strata to avoid contamination of the intervention and to balance the number of participants between the intervention and control group. Each hospital was then randomised into the intervention or control group.

The hospital and individual samples were drawn based on estimates of a power calculation, of which details have been described in the research protocol (A. Rau et al., 2018). Based on a pilot study by Khan et al. (2015), intra-cluster correlation coefficient was calculated at 0.05 and the coefficient for 
between groups variation was 0.25 . With an estimated design effect of 1.7 , the estimated sample size required for this study was 347 respondents in the intervention group and 237 in the control group. Based on previous experience of conducting research in the Free State province, 50\% over sampling was used to account for the expected loss to follow up. The follow-up measurement was done one year after the intervention (two years following the baseline measurement), tracking the same participants who participated at baseline. There were 882 respondents at baseline and at follow-up there were 652 respondents, a reduction of $26.1 \%$. This reduction in respondents was taken into account when regarding the over sampling in the designing stage of the study (A. Rau et al., 2018). The results presented in this paper are based on the 652 respondents who answered the questionnaire at the two time points.

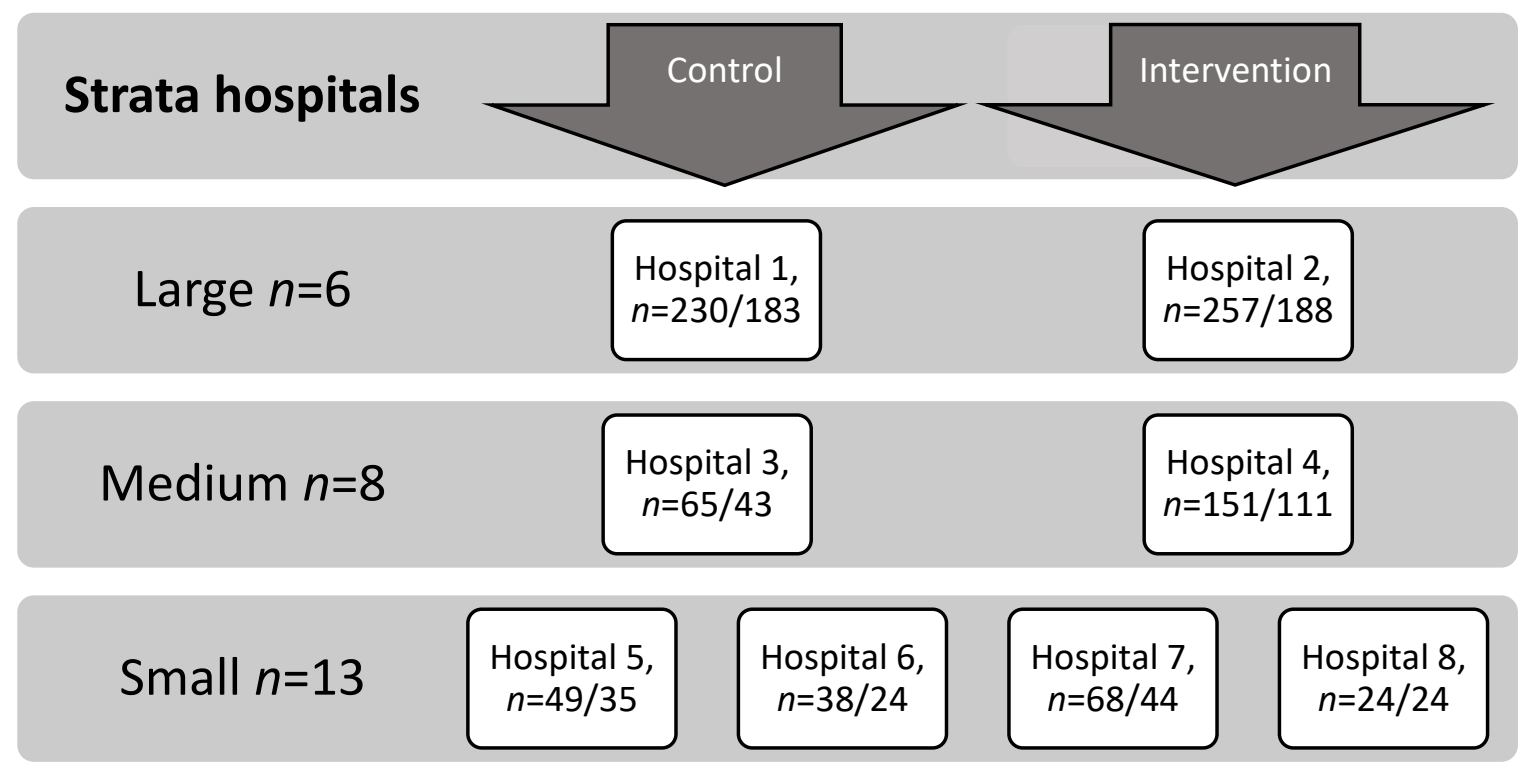

Figure 1. Description of the sampling of the 8 participating hospitals divided in sampling strata including the number of individual respondents answering to both baseline questionnaire/ and number who followed up. 


\section{Qualitative}

Participants were conveniently sampled from all who were trained in the social and behaviour change communication (SBCC) workshops. This sampling strategy created as little disruption as possible in the functioning of the hospitals. Effort was made to get participants from all job levels: Professional HCWs (doctors, nurses and allied health professionals such as social workers and physiotherapists); administrative and management staff; and support staff (e.g. porters, cleaners, security staff and household staff such as kitchen and laundry workers).

One hundred and fourteen participants were reached in 24 focus groups and two individual interviews, which were conducted in English and Sesotho. The focus groups were conducted about one year after the training workshop had taken place. The reason for the two individual interviews was that during some of the time slots allocated for focus groups, only two participants could attend, so we decided to conduct two separate individual interviews to improve the quality of the data.

\subsection{The intervention}

The intervention to reduce HIV and TB stigma among HCWs was based on a combination of SBCC components. They consisted primarily of a workshop for selected change agents among the HCWs and a hospital-wide social marketing campaign with a message to stop stigma.

\subsubsection{Theoretical background}

The intervention was based on the Diffusion of Innovations theory, which sets out to explain how, why and at what rate new ideas and technologies spread (Rogers, 2010). The theory proposes that social change is accelerated through change agents; individuals who people look up to and regard as role models and whose choices and actions are regarded as admirable and worthwhile emulating. As a consequence of this esteem, they are ideally positioned to promote change and diffuse new ideas and practices in social and organisational contexts (Dearing, 2009). More recently, researchers and practitioners in health education and health communications have taken up diffusion research, which 
was highlighted by a recent literature review by (Feyissa et al., 2019). Most relevant to our project is the recent research by Li et al. (2013b), who reduced HIV stigma among HCWs in public health facilities in China through the use of popular opinion leaders (Li et al., 2013a; Li et al., 2010). These were wellrespected co-workers who were trained to disseminate the message of the intervention through peerto-peer interactions with other colleagues and with patients. A similar strategy was applied to the present study.

\subsubsection{Intervention components}

The intervention to reduce HIV and TB stigma among HCWs, previously described in the study protocol (A. Rau et al., 2018), consisted of (1) a workshop for HCWs who would educate other HCWs on how to reduce stigma among their colleagues, conducted in either English or Sesotho; and (2) a social marketing campaign to help reinforce and disseminate the single key anti-stigma message in the workplace: 'Let's Stop Stigma - Be kind to yourself and others'. 'Be kind to yourself and others' was also translated into Afrikaans and Sesotho. The different parts of the intervention were developed and piloted in several steps. First, one study by Siegel et al. (2015) developed the initial sociocommunication material with the main graphic. Later, , in 2018, the campaign slogan and training materials were refined in several consultations with a special Department of Health steering committee set up to oversee the intervention. The workshop with change agents was piloted at one of the intervention hospitals.

In the SBCC intervention, participating HCWs were (1) taught about different forms and effects of HIV and TB stigma and the related health rights and responsibilities in the workplace and (2) equipped to start conversations about HIV and TB stigma in the workplace with co-workers. This was underpinned through an exercise in confronting one's own beliefs, values, attitudes and behaviours. They were also (3) taught how to respond to stigmatising situations they encounter in the workplace (see public intervention facilitators guide A Rau et al. (2016)). In addition, they received social marketing materials (e.g. branded wristbands and pens) to support their stigma-reduction 
communications. The trained HCWs were heads of departments and employees who had been nominated for their special capacities as change agents, primarily through the use of positional and snowball sampling (Valente \& Pumpuang, 2007). Positional leaders were identified through asking hospital CEOs to provide names of the most influential staff on all managerial levels. The staff identified those who agreed to be trained as change agents, then nominated who they thought would fit as change agents and those who were interested in turn nominated co-workers whom they thought would be suitable.

There was also a wider visible social marketing campaign, including posters that the HCWs could point to, to spark conversations or highlight what they are saying. Medical doctors who were not able to attend the general staff trainings were educated in HIV and TB stigma through power-point presentations based on the workshop materials and delivered by a fellow medical doctor who is a project member as well as an employee at the Free State Department of Health. The theory behind the intervention hypothesised that the knowledge and skills acquired in the trainings, amplified by social marketing, would decrease stigma levels across the hospitals and improve the health environment of the workplace.

\section{Input}

Hiring and training of workshop facilitators

Training manual and associated teaching materials designed and SBCC Social marketing materials designed (items with Stop Stigma-message: pens, wristbands, fridge-magnets, chocolate wrappers, posters) Recruitment of change agents.

\section{Output/activities}

Training of change agents in workshops. 543 (49.2\% of the hospital staff in the intervention hospitals).

Change agents' diffusion of innovation of the no-stigma message to colleagues.

Information material diffused in hospitals and directly to change agents, working as awareness raising as well as conversation starters for change agents.

\section{Primary outcome}

Decrease in HIV and TB stigma among HCWs.

\section{Secondary outcome}

Improved environment in which HCWs seek care. 
Figure 2. Logic model for intervention to decrease stigma in healthcare workers, the Free State, South Africa.

\subsection{Data collection}

\subsubsection{Quantitative}

The baseline data were collected in autumn 2016 and the follow-up data were collected in autumn 2018. Questionnaires were used at both times. Respondents had to give written consent and fill in the questionnaires independently in English, Sesotho or Afrikaans. For respondents with low levels of reading literacy, the fieldworkers worked through the questions verbally and answered any queries in small group sessions. Fieldworkers experienced in health research were given additional training on ethics and standardisation of the research processes. Before returning the questionnaire to the fieldworker, the participants placed it in a sealed envelope to ensure anonymity.

\subsubsection{Qualitative}

In the four intervention sites where quantitative data previously had been gathered, focus groups were held with change agents who had participated in the SBCC training workshops. The qualitative data were gathered primarily through focus groups but in one case when insufficient numbers attended the focus group, individual interviews were carried out instead. Most participants attending Englishspeaking groups were healthcare professionals and administrators, while most Sesotho-speaking focus groups were made up of non-professional support staff. Each focus group participant chose a number by which they were addressed throughout the focus group to protect confidentiality. A semi-structural focus group guide was used (see supplementary file) and two researchers facilitated each focus group; 
of whom at least one understood Sesotho. The researchers conducting the focus groups and interviews had all been trained on the specific topic and held at least a Master's degree.

\subsection{Measures}

Stigma

This study analysed external stigma, which refers to stigmatising others either through perceptions, attitudes or behaviours. Four previously validated measures were used to analyse stigma. These measures have previously been developed from pilot data and later developed and refined based on the baseline data (E Wouters et al., 2017; Edwin Wouters et al., 2016). Respondents' External HIV Stigma (HIV-REXT), comprising of four items and Respondents' External TB Stigma (TB-REXT), comprised of three items, measures the respondents' own stigmatising attitudes towards colleagues with HIV or TB. Other Co-workers' External HIV Stigma (HIV-OEXT) comprising of four items and Other Co-workers' External TB Stigma (TB-OEXT) comprising of five items, measures how the respondents perceive the general attitudes of other co-workers towards co-workers with HIV or TB (E Wouters et al., 2017).

In addition to previous instrument validation, we also calculated Cronbach's Alpha for internal reliability of the instrument. Sum scores were created for each stigma domain consisting of questions on a four-point Likert scale (1. Strongly disagree, 2. Disagree, 3. Agree and 4. Strongly agree). Because the questions were asked in different directions, the responses were recoded so that (1) means the lowest stigma and (4) the highest. Theoretically, this would indicate that an outcome of 2 on the stigma scale would mean that the respondent generally disagreed with the stigma-related statements of a certain instrument. The average sum score was then divided by the number of items in each instrument to make them comparable with each other. Averages were used as the outcome distribution was similar to the normal distribution.

\section{Control variables}


Sex was measured as a dummy variable with male (0) and female (1). Race was constructed as four categories, which are common for reporting race in South Africa: Black, White, Coloured and Asian. Coloured is a recognised term that means people of mixed race. Education level was measured in six categories of highest completed degree level: No education, Primary (year 1-6), Secondary (year 7-9), Matric (graduation from high school after year 12), Diploma (postgraduate qualification) and Degree (e.g. Undergraduate, Master's, M.Phil or Ph.D.). Years working in the hospital was measured through the years that the respondent stated that they had worked in the hospital at the time of the follow-up measurement.

\subsection{Analysis}

\subsubsection{Statistical data analysis}

The analysis of the intervention effect on the different stigma scales followed the principles of Hayes and Moulton (2009). The intervention effect was analysed based on cluster-level summaries of the stigma measurements, using a two-stage cluster level approach. This approach was chosen because individual-level analyses do not tend to perform robustly with a small number of clusters, such as in this study with eight hospitals as experimental units (Hayes \& Moulton, 2009). The software SPSS Statistics 25 was used for the analyses. In the first stage, we carried out an ordinary least square linear regression (OLS) because the stigma outcome measure is continuous. We controlled for age, sex and took into account the stratified study design (based on hospital size). We also added baseline cluster summaries of the outcome to account for possible imbalances at baseline.

Missing cases were treated with listwise deletion, as they never amounted to the deletion of more than $1 \%$ of cases per stigma outcomes (see table 2 ). The same regression analysis was performed for each of the stigma outcomes and the residuals (the difference between observed and expected value) were aggregated and saved into new cluster-level variables.

In the second stage, the mean residual for each hospital were aggregated to create a new dataset. At that point, the baseline difference in stigma, study design and other control variables had 
been taken into account and the analysis of the intervention effect could take place on a cluster level. Because there were only four clusters per arm and a normal distribution could not be assumed, a nonparametric test (Mann-Whitney) was used to identify whether there was a significant difference between intervention and control arm (Conroy, 2012). This test assigns a rank from lowest to highest value to each observed dependent value and compares the summed ranks of the two groups to calculate the test statistic $U$. It tests whether there is a difference in the outcome between the intervention and control group. It uses equation 1 , where $n$ is the sample size for each group and $R_{i}$ are the ranks.

$$
U=n_{1} n_{2}+\frac{n_{2}\left(n_{2}+1\right)}{2}-\sum_{i=n_{1}+1}^{n_{2}} R_{i}(1)
$$

The effect size reported from the Mann-Whitney test was the rank-biserial correlation, which is the easiest to interpret. The effect statistic $r$ (equation 2) can be calculated from the Mann-Whitney $U$ (Wendt, 1972) and shows the correlation of the proportion of the ranked pairs of observation that favours the hypothesised direction.

$$
r=\frac{2 U}{n_{1} n_{2}}(2)
$$

\subsubsection{Qualitative analysis}

Data from the focus groups and two individual in-depth qualitative interviews were transcribed (and where needed translated to English) and then exported to QSR International's NVivo 12 software, which was released in 2018. To ensure inter-rater reliability of the analysis, a proportion (ca $5 \%$ ) of the focus group material was double-coded by two co-authors. The two coders were in substantial agreement (Kappa 0.83). The transcripts were coded and analysed deductively based on theoretically defined codes and inductively based on new insights that emerged and that led to new, unexpected codes (Fereday \& Muir-Cochrane, 2006). Some local expressions and sayings in Sesotho were explained 
to the analyst by the translator. Overarching analytical categories were (i) how, since the training, participants identified stigma in the workplace, (ii) examples of how they had applied methods from the workshops to reduce stigma, (iii) how they had utilised the social marketing campaign and (iv) challenges to reduce stigma in the workplace. We were interested in mechanisms of change according to the diffusion of innovation theory that the intervention was modelled after; hence, in the analysis, we were interested in concrete examples and stories of change/obstacles rather than general opinions about whether the intervention worked. These data were also inductively analysed for new codes based on questions we had about workplace stigma and the intervention but allowing for new emerging themes to arise. The two individual interviews were of the character that for this purpose, they could be analysed with the same coding scheme as the focus groups. The data of the two individual interviews did not contradict the overall findings of the focus groups and no quotes were chosen to represent the findings for this paper.

\section{Results}

\subsection{Implementation of the intervention}

The interventions went as planned and described in the protocol (A. Rau et al., 2018). First, all sites were visited and key role players consulted to explain interventions in detail, address any concerns and questions, establish when interventions could begin and how they would be managed in terms of reaching staff and arranging intervention venues.

Working with approved schedules and through designated staff in key positions, the intervention team (six people) put up posters in high-traffic areas of the hospitals and distributed selected SBCC materials (stigma-campaign branded pens, chocolates and wristbands) to all staff in all intervention sites. Workshops were then held and additional SBCC materials were distributed to participants. The workshops were conducted in English and Sesotho and followed the steps outlined in the facilitator manual (A Rau et al., 2016). In total, 523 HCWs were trained (49.2\% of the total population of HCWs at the four intervention hospitals). The workshops were planned together with 
the hospital administrations to minimise any interruption to the hospital. A reoccurring challenge was to organise the training workshops around the HCWs' working hours as certain wards and departments suffered critical staff shortage. This made it difficult to train certain staff, such as midwives from the labour ward, even if they had previously consented to participate. Some HCWs chose to attend the training outside of their ordinary working hours. To minimise the impact on the personnel coverage as well as time and budget, the workshops were limited to four hours in length.

\subsection{Descriptive statistics}

Table 1. Descriptive characteristics of the control group vs the intervention group, at final measurement. As the allocation of clusters between arms is carried out randomly, any differences that do occur are assumed to be by chance

\begin{tabular}{|c|c|c|c|}
\hline & $\begin{array}{l}\text { Control group } \\
n=285\end{array}$ & $\begin{array}{l}\text { Intervention } \\
\text { group } \\
n=367\end{array}$ & $\begin{array}{l}\text { Total } \\
N=652\end{array}$ \\
\hline $\begin{array}{l}\text { Age (mean, std. } \\
\text { div) }\end{array}$ & $43.6(9.3)$ & $46.2(9.1)$ & $45.1(9.3)$ \\
\hline \multicolumn{4}{|l|}{ Sex, $n(\%)$} \\
\hline Male & $86(32.2)$ & $99(27.1)$ & $185(28.5)$ \\
\hline Female & $199(69.8)$ & 266 (72.9) & 465 (71.5) \\
\hline \multicolumn{4}{|l|}{ Race, $n(\%)$} \\
\hline Black & $253(88.8)$ & 326 (88.9) & $579(88.9)$ \\
\hline White & $25(8.8)$ & $24(6.5)$ & $49(7.5)$ \\
\hline Coloured & $6(2.1)$ & $15(4.1)$ & $21(3.2)$ \\
\hline Asian & $1(0.4)$ & $2(0.5)$ & $3(0.5)$ \\
\hline \multicolumn{4}{|l|}{ Education, $n$ (\%) } \\
\hline None & $1(0.4)$ & $1(0.3)$ & $2(0.3)$ \\
\hline Primary & $10(3.5)$ & $21(5.7)$ & $31(4.8)$ \\
\hline Secondary & $44(15.4)$ & 66 (18.0) & 110 (16.9) \\
\hline Matric & $108(37.9)$ & $136(37.1)$ & $244(37.4)$ \\
\hline Diploma & 75 (26.3) & $98(26.7)$ & $173(26.5)$ \\
\hline Degree & $47(16.5)$ & 45 (12.3) & $92(14.1)$ \\
\hline $\begin{array}{l}\text { Years working at } \\
\text { the hospital } \\
\text { (mean, std. div) }\end{array}$ & $10.8(6.9)$ & $15.3(10.3)$ & $13.3(9.2)$ \\
\hline
\end{tabular}

Table 1 describes descriptive characteristics of the study sample divided by intervention and control groups. Table 2 shows indicators for how each stigma-measuring item performed in both of the intervention-control groups at baseline and follow-up. 
The instrument for 'Respondents' external HIV stigma' showed high reliability with Cronbach's $\propto 0.78$ at baseline and 0.81 at follow up according to the commonly used criteria that Cronbach's $\propto$ over 0.7 indicates good reliability (Santos, 1999). The stigma levels based on hospital averages were at baseline 1.64 for the control group and 1.71 for the intervention group. It increased slightly by the follow-up measurement in both groups, with 1.66 in the control group and 1.72 in the intervention group.

'Respondents' external TB stigma' was based on only three items and did not show as good reliability as the previously mentioned measures, now with Cronbach's $\propto 0.61$ at baseline and 0.59 at follow-up. These low $\propto$-levels should call into question whether the measure is appropriate for measuring the intended phenomenon, but could also be caused by a low number of items. This was similarly found in the original measurement article by E Wouters et al. (2017). The stigma levels were slightly higher than those of external HIV stigma with hospital-collapsed baseline values of 1.91 for the control group and 1.93 for the intervention group. In both groups, the hospital-average stigma levels had decreased at follow-up, with 1.88 for the intervention group and 1.86 for the control group.

\section{Co-workers external stigma}

Co-workers external HIV stigma measured the degree of stigmatising behaviour that the respondent had witnessed being enacted by colleagues in the hospital. The reliability of the measure proved good at both time points with Cronbach's $\propto$ of 0.79 at baseline and 0.81 at follow-up. The baseline measurement showed that individual item means were very similar between intervention and control group, and the hospital means combined were 1.97 for the control group and 2.03 for the intervention group. The follow-up showed a small reduction in stigma in both groups with 1.89 in the control group and 1.99 in the intervention group.

The stigma levels of 'Co-workers' external TB stigma' showed similar scores to those for the equivalent HIV stigma scale. The measurement showed high reliability with $\propto 0.84$ at baseline and 0.82 at follow-up. The hospital-based collapsed mean was similar between intervention and control group at baseline with 2.02 for control and 2.00 for the intervention group. The hospital means were slightly 
lower in both groups at follow-up measurement with 1.98 in the control and 1.99 in the intervention group. 
Table 2. Descriptive statistics of the stigma measures presented at the time of measurements, intervention-control and measurement level. Showing means (std. div)

\begin{tabular}{|c|c|c|c|c|c|c|c|c|}
\hline & \multicolumn{4}{|c|}{ Baseline measurement } & \multicolumn{4}{|c|}{ Follow-up measurement } \\
\hline & \multicolumn{2}{|c|}{ Individual } & \multicolumn{2}{|c|}{ Hospital-level } & \multicolumn{2}{|c|}{ Individual } & \multicolumn{2}{|c|}{ Hospital-level } \\
\hline & \multicolumn{2}{|c|}{$n=652($ missing 0$)$} & \multicolumn{2}{|c|}{$n=8$} & \multicolumn{2}{|c|}{$n=652$ (missing 3$)$} & \multicolumn{2}{|c|}{$n=8$} \\
\hline $\begin{array}{l}\text { Respondents' external HIV stigma } \\
\text { Cronbach's } \propto \text { : baseline } 0.78 \text {. Cronbach's } \propto \text { : follow-up } 0.81\end{array}$ & $\begin{array}{c}\text { Control } \\
n=285\end{array}$ & $\begin{array}{l}\text { Intervention } \\
n=367\end{array}$ & $\begin{array}{c}\text { Control } \\
n=4\end{array}$ & $\begin{array}{c}\text { Intervention } \\
n=4\end{array}$ & $\begin{array}{c}\text { Control } \\
n=285\end{array}$ & $\begin{array}{l}\text { Intervention } \\
\quad n=367\end{array}$ & $\begin{array}{c}\text { Control } \\
n=4\end{array}$ & $\begin{array}{c}\text { Intervention } \\
n=4\end{array}$ \\
\hline $\begin{array}{l}\text { I would feel comfortable having HCW who are known to be HIV- } \\
\text { positive working closely with me in my job }\end{array}$ & $\begin{array}{l}1.84 \\
(0.78)\end{array}$ & $1.91(0.78)$ & & & $\begin{array}{l}1.95 \\
(0.80)\end{array}$ & $1.97(0.85)$ & & \\
\hline HCW who have HIV should not feel guilty about it & $\begin{array}{c}1.64 \\
(0.77)\end{array}$ & $1.69(0.77)$ & & & $\begin{array}{c}1.68 \\
(0.77)\end{array}$ & $1.68(0.76)$ & & \\
\hline HIV-positive HCW can be good role models in the workplace & $\begin{array}{c}1.55 \\
(0.67)\end{array}$ & $1.68(0.73)$ & & & $\begin{array}{c}1.65 \\
(0.69)\end{array}$ & $1.70(0.73)$ & & \\
\hline $\begin{array}{l}\text { Doctors and nurses with HIV who are otherwise in good health } \\
\text { should continue to practice medicine }\end{array}$ & $\begin{array}{l}1.47 \\
(0.65)\end{array}$ & $1.54(0.64)$ & & & $\begin{array}{c}1.58 \\
(0.68)\end{array}$ & $1.59(0.69)$ & & \\
\hline \multirow[t]{4}{*}{ Sum score } & & & 1.64 & 1.71 & & & 1.66 & 1.72 \\
\hline & \multicolumn{4}{|c|}{ Baseline measurement } & \multicolumn{4}{|c|}{ Follow-up measurement } \\
\hline & \multicolumn{2}{|c|}{ Individual } & \multicolumn{2}{|c|}{ Hospital-level } & & dividual & \multicolumn{2}{|c|}{ Hospital-level } \\
\hline & \multicolumn{2}{|c|}{$n=652($ missing 1$)$} & \multicolumn{2}{|c|}{$n=8$} & \multicolumn{2}{|c|}{$n=652($ missing 5$)$} & \multicolumn{2}{|c|}{$n=8$} \\
\hline $\begin{array}{l}\text { Respondents' external TB Stigma } \\
\text { Cronbach's } \propto \text { baseline } 0.61 \text {. Cronbach's } \propto \text { follow-up } 0.59\end{array}$ & $\begin{array}{l}\text { Control } \\
n=285\end{array}$ & $\begin{array}{l}\text { Intervention } \\
\quad n=367\end{array}$ & $\begin{array}{c}\text { Control } \\
n=4\end{array}$ & $\begin{array}{c}\text { Intervention } \\
n=4\end{array}$ & $\begin{array}{l}\text { Control } \\
n=285\end{array}$ & $\begin{array}{l}\text { Intervention } \\
\qquad n=367\end{array}$ & $\begin{array}{l}\text { Control } \\
n=4\end{array}$ & $\begin{array}{c}\text { Intervention } \\
n=4\end{array}$ \\
\hline $\begin{array}{l}\text { I do not want to work together with co-workers who are on TB } \\
\text { treatment }\end{array}$ & $\begin{array}{c}1.73 \\
(0.72)\end{array}$ & $1.72(0.66)$ & & & $\begin{array}{c}1.68 \\
(0.61)\end{array}$ & $1.65(0.67)$ & & \\
\hline I am cautious of co-workers who are on TB treatment & $\begin{array}{l}2.30 \\
(0.83)\end{array}$ & $2.38(0.81)$ & & & $\begin{array}{l}2.16 \\
(0.76)\end{array}$ & $2.23(0.85)$ & & \\
\hline $\begin{array}{l}\text { If I think a co-worker has TB, I will avoid eating or drinking in the } \\
\text { same room }\end{array}$ & $\begin{array}{l}1.76 \\
(0.67)\end{array}$ & $1.82(0.70)$ & & & $\begin{array}{c}1.80 \\
(0.64)\end{array}$ & $1.71(0.68)$ & & \\
\hline \multirow[t]{4}{*}{ Sum score } & & & 1.91 & 1.93 & & & 1.88 & 1.86 \\
\hline & \multicolumn{4}{|c|}{ Baseline measurement } & \multicolumn{4}{|c|}{ Follow-up measurement } \\
\hline & \multicolumn{2}{|c|}{ Individual } & \multicolumn{2}{|c|}{ Hospital level } & \multicolumn{2}{|c|}{ Individual } & \multicolumn{2}{|c|}{ Hospital level } \\
\hline & \multicolumn{2}{|c|}{$n=652$ (missing 2) } & \multicolumn{2}{|r|}{$n=8$} & \multicolumn{2}{|c|}{$n=652$ (missing 3 ) } & \multicolumn{2}{|c|}{$n=8$} \\
\hline
\end{tabular}




\begin{tabular}{|c|c|c|c|c|c|c|c|c|}
\hline $\begin{array}{l}\text { Co-workers' external HIV stigma } \\
\text { Cronbach's } \propto \text { follow up } 0.81\end{array}$ & $\begin{array}{l}\text { Control } \\
n=285\end{array}$ & $\begin{array}{l}\text { Intervention } \\
\quad n=367\end{array}$ & $\begin{array}{c}\text { Control } \\
n=4\end{array}$ & $\begin{array}{l}\text { Intervention } \\
\quad n=4\end{array}$ & $\begin{array}{l}\text { Control } \\
n=285\end{array}$ & $\begin{array}{l}\text { Intervention } \\
\qquad n=367\end{array}$ & $\begin{array}{c}\text { Control } \\
n=4\end{array}$ & $\begin{array}{l}\text { Intervention } \\
\quad n=4\end{array}$ \\
\hline $\begin{array}{l}\text { Some of my co-workers in this hospital look down on healthcare } \\
\text { workers (HCW) who they think may be HIV-infected }\end{array}$ & $2.01(0.83)$ & $2.03(0.81)$ & & & $\begin{array}{c}1.97 \\
(0.75)\end{array}$ & $1.98(0.78)$ & & \\
\hline $\begin{array}{l}\text { There are HCW who make negative remarks about the health of } \\
\text { co-workers who are involved in HIV care and treatment }\end{array}$ & $\begin{array}{c}2.16 \\
(0.85)\end{array}$ & $2.15(0.82)$ & & & $\begin{array}{c}2.11 \\
(0.85)\end{array}$ & $2.09(0.81)$ & & \\
\hline $\begin{array}{l}\text { Some HCW who are suspected of having HIV get rejected by } \\
\text { others in the workplace }\end{array}$ & $\begin{array}{c}1.99 \\
(0.73)\end{array}$ & $2.00(0.78)$ & & & $\begin{array}{c}1.89 \\
(0.71)\end{array}$ & $2.05(0.80)$ & & \\
\hline $\begin{array}{l}\text { Other healthcare workers in this hospital are afraid of catching HIV } \\
\text { from colleagues who care for HIV-positive patients }\end{array}$ & $\begin{array}{c}2.05 \\
(0.82)\end{array}$ & $2.05(0.83)$ & & & $\begin{array}{c}1.97 \\
(0.74)\end{array}$ & $1.99(0.78)$ & & \\
\hline \multirow[t]{4}{*}{$\begin{array}{l}\text { Sum score mean } \\
(n=649 . \text { Missing excluded }=3)\end{array}$} & & & 1.97 & 2.03 & & & 1.89 & 1.99 \\
\hline & \multicolumn{4}{|c|}{ Baseline measurement } & \multicolumn{4}{|c|}{ Follow-up measurement } \\
\hline & \multicolumn{2}{|c|}{ Individual } & \multicolumn{2}{|c|}{ Hospital level } & \multicolumn{2}{|c|}{ Individual } & \multicolumn{2}{|c|}{ Hospital level } \\
\hline & \multicolumn{2}{|c|}{$n=652$ (missing 2) } & \multicolumn{2}{|c|}{$n=8$} & \multicolumn{2}{|c|}{$n=652$ (missing 5$)$} & \multicolumn{2}{|c|}{$n=8$} \\
\hline $\begin{array}{l}\text { Co-workers' external TB stigma } \\
\text { Cronbach's } \propto \text { : follow up } 0.82 \quad \text { Cronbach's } \propto: .: \text { baseline } 0.84 \text {. }\end{array}$ & $\begin{array}{l}\text { Control } \\
n=285\end{array}$ & $\begin{array}{c}\text { Intervention } \\
\quad n=367\end{array}$ & $\begin{array}{c}\text { Control } \\
n=4\end{array}$ & $\begin{array}{c}\text { Intervention } \\
n=4\end{array}$ & $\begin{array}{c}\text { Control } \\
n=285\end{array}$ & $\begin{array}{c}\text { Intervention } \\
\quad n=367\end{array}$ & $\begin{array}{c}\text { Control } \\
n=4\end{array}$ & $\begin{array}{l}\text { Intervention } \\
\quad n=4\end{array}$ \\
\hline $\begin{array}{l}\text { HCW who are suspected of having TB are stigmatised in this } \\
\text { hospital }\end{array}$ & $\begin{array}{c}2.01 \\
(0.76)\end{array}$ & $1.98(0.76)$ & & & $\begin{array}{c}2.02 \\
(0.77)\end{array}$ & $2.03(0.74)$ & & \\
\hline $\begin{array}{l}\text { Some HCW in this hospital avoid contact with co-workers who they } \\
\text { think may have TB }\end{array}$ & $\begin{array}{l}1.95 \\
(0.73)\end{array}$ & $1.99(0.74)$ & & & $\begin{array}{l}1.99 \\
(0.76)\end{array}$ & $2.00(0.69)$ & & \\
\hline $\begin{array}{l}\text { Some HCW in this hospital would not want to eat or drink with a co- } \\
\text { worker who they think has TB }\end{array}$ & $\begin{array}{l}2.13 \\
(0.81)\end{array}$ & $2.19(0.89)$ & & & $\begin{array}{c}2.13 \\
(0.79)\end{array}$ & $2.06(0.80)$ & & \\
\hline $\begin{array}{l}\text { Some HCW in this hospital are stigmatised when others find out } \\
\text { that they have gone for TB screening }\end{array}$ & $\begin{array}{l}2.05 \\
(0.79)\end{array}$ & $\begin{array}{c}1.99 \\
(0.78)\end{array}$ & & & $\begin{array}{l}2.05 \\
(0.79)\end{array}$ & $1.99(0.75)$ & & \\
\hline $\begin{array}{l}\text { I have noticed that some other HCW in this hospital feel } \\
\text { uncomfortable to work near co-workers with TB }\end{array}$ & $\begin{array}{l}2.09 \\
(0.79)\end{array}$ & $2.16(0.87)$ & & & $\begin{array}{l}2.06 \\
(0.76)\end{array}$ & $2.04(0.80)$ & & \\
\hline Sum score & & & 2.02 & 2.00 & & & 1.98 & 1.99 \\
\hline
\end{tabular}




\subsection{Rank sum test results}

Table 3 shows the results of the rank sum tests and whether the intervention had a significant effect on the different stigma scales. There was no significant intervention effect on the HIV-REXT $(U=4$, $p=0.34$ ), and the rank-biserial correlation of the ranks showed an effect size of $r=0.50$ in the direction that stigma was lower in the control group compared to the intervention. Likewise, no significant intervention effect was found for the TB-REXT, had similar estimates because the rank distribution followed the same pattern as for HIV-OEXT with $(U=5$ and $p=0.49)$. The rank-biserial correlation estimate was again $r=0.38$ but this time with the higher stigma in the control group.

Neither did HIV-OEXT show an intervention effect $(U=5$ and $p=0.49)$, even if the effect size $(r=0.38)$ was in the direction that hospital-level stigma scores tended to be higher in the intervention group. For the equivalent TB scale, TB-OEXT, the rank sum test did not show a significant difference between the intervention and control group $(U=6, p=0.69)$. The summed ranks gave rank-biserial correlation of 0.25 , indicating a distribution where stigma was higher in the intervention group.

Table 3. Rank sum test of difference in cluster-level stigma Z-scores between the intervention and control group*

\begin{tabular}{|c|c|c|c|c|c|c|}
\hline & $\begin{array}{l}\text { Intervention } \\
\text { Arm }(N=8,4 \\
\text { in each arm })\end{array}$ & $\begin{array}{l}\text { Mean } \\
\text { stigma } \\
\text { Z-score } \\
\text { residual }\end{array}$ & $\begin{array}{l}\text { Mean } \\
\text { Rank }\end{array}$ & Sum of Ranks & $\begin{array}{c}\text { Mann- } \\
\text { Whitney U } \\
\text { (Exact sig. 2- } \\
\text { tailed } p \text {-value) }\end{array}$ & $\begin{array}{l}\text { Rank-biserial correlation } \\
(r)\end{array}$ \\
\hline \multirow{3}{*}{$\begin{array}{l}\text { HIV- } \\
\text { REXT }\end{array}$} & Control & -0.355 & 3.50 & 14.00 & & \\
\hline & Intervention & 0.225 & 5.50 & 22.00 & & \\
\hline & Diff & & & & $4(0.34)$ & 0.50 \\
\hline \multirow[t]{3}{*}{ TB-REXT } & Control & 0.085 & 5.25 & 21.00 & & \\
\hline & Intervention & -0.195 & 3.75 & 15.00 & & \\
\hline & & & & & $5(0.49)$ & -0.38 \\
\hline \multirow{3}{*}{$\begin{array}{l}\text { HIV- } \\
\text { OEXT }\end{array}$} & Control & -0.655 & 3.75 & 15.00 & & \\
\hline & Intervention & 0.165 & 5.25 & 21.00 & & \\
\hline & & & & & $5(0.49)$ & 0.38 \\
\hline \multirow[t]{3}{*}{ TB-OEXT } & Control & -0.235 & 4.00 & 16.00 & & \\
\hline & Intervention & -0.1125 & 5.00 & 20.00 & & \\
\hline & & & & & $6(0.69)$ & 0.25 \\
\hline
\end{tabular}


*Based on Z-scores obtained from individual level regression controlling for baseline stigma level, stratification in sampling, age and sex.

\subsection{Qualitative findings}

The quantitative results did not indicate any measurable effect of the intervention on the reduction of stigma on any of the scales measured. This result does not exclude the possibility that the intervention worked on individual occasions, as implied in the qualitative results given below. Qualitative data were further gathered to be able to understand the mechanisms underlying the intervention once the change agents received the training and the researchers left the hospitals. We look at the qualitative data to find potential explanations of challenges that might have hindered the effect. The qualitative results also gave several examples of when the intervention did work, which increases the understanding of the results as these cases are 'hidden' in the quantitative results. Below are examples of when the intervention did and did not work and of obstacles reported by the focus group participants.

\section{Social hierarchies among healthcare workers}

Even if several focus group participants stated that the intervention had helped them to reduce stigma in the hospital, on several occasions the difficulty of addressing certain co-workers was identified as a challenge. Particularly, within hospitals, the hierarchical organisation can foster a hostile environment when HCWs try to manage and control each other (Johnson, 2009). As the mechanism of change for spreading the intervention was on an interpersonal level between HCWs, the underlying interpersonal relationships between the colleagues were important. Established formal or informal hierarchies were barriers to calling out stigmatising attitudes or behaviour.

'So, like basically you know what, you can teach us what is supposed to be done and then if we go and say let's try to implement this to those who have already been there, they won't take it. [...] going to say you know what, he's coming with his clever thing of reading a book or 
whatever, so what's he going to teach me? I've been here for quite a long time. So, what am I going to say? I've been here for only ten years in the workplace to someone who's got twentyfive years? [...] You see? There's nothing you're going to change. They're going to say you stay there, we're going to do our own thing which we've been doing for quite a long time, you do your own thing'.

Male HCW

Some respondents also expressed fear that if they called out a co-worker, they might become defensive and turn against you. Some HCWs did not want to put themselves in that position.

'[...] if you entertain to such conflicts you end up being the one attacked while you were trying to help, but it turns against you. Rather look at it and just pray for them'.

Female HCW

\section{Difficulty of criticising friends}

Reducing stigma in the workplace sometimes involved pointing out that something that a peer is doing is wrong or negative. Having a bad relationship with a co-worker could be a barrier to challenging their behaviour, but so could being in a close or friendly relationship. As this female HCW states, it can be difficult to be outspoken in calling out stigma among friends.

'[...] I think it's a big challenge because sometimes you think maybe I heard and what I said, that person is my friend, it's a very big challenge to go to that person and say why are you saying it that it will be a big juggle around the words so, it's a very big challenge, especially around the work'.

Female HCW 
In general, a challenge with trying to reduce HIV and TB stigma in the workplace often required one to put oneself in a socially or professionally vulnerable position. This might be more difficult in a relatively closed workplace situation, such as the hospital, where, even if something goes wrong in the interpersonal relationship, they still need to face each other every day.

\section{Difficulty of understanding the word 'stigma'}

Various worded messages for the social marketing campaign were tested in a pilot study to identify the most impactful visual message and wording (Siegel et al., 2015). The campaign slogan and materials were then debated at length and refined in consultations with the Special intervention Steering Committee, most of whom were first-language Sesotho speakers. Although all instruments were also professionally translated and back-translated, there is no precise equivalent of the word 'stigma' in Sesotho. Despite the fact that the word 'stigma' has been used in large-scale national research (Simbayi et al., 2015)and in nation-wide interventions (Rohleder et al., 2009)some HCWs were not familiar with the word prior to the training

...Even if you did not give us examples when we came to the first training, we were lost. Like when somebody said do you know what is stigma? It's like a new disease itself.

\section{Female HCW}

It seemed that stigma was not a concept that all participants were confident using even after the training. This could have made some of them less comfortable with using the word, and conducting anti-stigma conversations with their peers, for rear of of sounding too 'lecturing'.

It's difficult in English. I was thinking about that when you were saying that, somebody will tell you how to treat your kids at home, that person is a scientist. He or she doesn't even have kids but in a thick book she will tell you how to deal with your kids. So, don't come up with those difficult words, come closer to us. 


\section{Indications that the intervention had worked}

The qualitative data provided insights into how the intervention made a difference in certain individuals' lives. Some of the HCWs said that the stigma training and hospital-wide campaign to end stigma had opened their eyes on how stigma affects people in the workplace. They remembered various aspects from the training, particularly that one should not look down on or gossip about someone with HIV or TB.

'You know what, before this research study, it has never come to our mind that we need to talk about this. It was never communicated to staff, but after that time I could even hear people talking about this thing of stigma. Most of the people they started hearing and understanding what is stigma and how it affects other people. I think it really assisted around that'.

Female HCW

However, when the change agents were asked if they had intervened or done something to stop stigma in the hospital, few gave concrete examples. Some HCWs described having really intervened when they came across stigmatising behaviour from other colleagues or stopped behaviours of their own that, after the training, they had identified as stigmatising.

The training has helped me a lot because I was able to confront someone; I called her aside and privately rebuked her. In addition, she quickly stopped what she was doing and now when she sees me she calls me Mrs. Stigma. Whenever she tried to do something, I would stare at her and she would stop.

Female HCW

Change agents often mentioned what they had talked about stigma and explained what they had learned to others outside the hospitals. In several cases, they had talked about stigma to their children 
or families who asked about the social marketing materials of the intervention such as pens and wristbands. Several HCWs had also spread the 'Stop Let's Stop Stigma - Be kind to yourself and others' message to their churches or supported friends or neighbours with HIV or TB.

\section{Discussion}

This cluster-randomised trial aimed to reduce HIV- and TB-stigma among HCWs in the Free State province of South Africa by means of an SBCC intervention. The quantitative results could not confirm a statistically significant reduction in stigma. Below some potential explanations, which are supported by the qualitative focus group study, are outlined. A crucial aspect of the intervention, based on Diffusion of Innovations theory, was the use of change agents who were trained to spread knowledge and messages about HIV and TB stigma in their workplace (Dearing, 2009; Rogers, 2010) (see Figure 2). According to our theoretical framework, the change agents should diffuse the intervention to make a substantial impact across the hospitals. . Some HCWs felt that it was not their place to talk to coworkers who were older or of a higher rank than themselves, and that they would not be taken seriously. Since we anticipated that HCWs might not reduce stigma across-ranks, HCWs from all ranks had participated in the trainings.

During the focus groups with the support staff, they often requested that all HCWs, particularly managers and those of higher positions, receive the stigma training. This suggests that many participants valued their intervention's training. However, training all staff was beyond the scope of this project, and potentially problematic in terms of time, given that public hospitals are busy and understaffed. The interviewed workers sometimes did not feel that it was their place to talk to coworkers older or of a higher rank than themselves, and that they would not be taken seriously. The recruitment process of change agents was supposed to target influential individuals, but this process might be hard to oversee and control without detailed knowledge of the characteristics of those being recruited and the formal hierarchies in which they operate. Stangl et al. (2019) highlights the relevance of intersecting stigmas in a new framework. In the qualitative data, it became apparent that professional rank, position and social status could intersect with anti-HIV- and TB-stigma 
communication. Thus, addressing other power structures, such as making sure to train the top management, could also be beneficial to the intervention.

It is interesting that many of the HCWs would rather talk about the intervention and use the social marketing material with family members and others in their community, such as neighbours or at their local church, than in their workplace. Outside the workplace, it was possible for them to stand out in a position of knowledge and influence to communicate with others, which they might not have been afforded in the workplace. They also suggested that HIV-and TB-stigma was more prevalent in their communities and that stigma-reducing efforts should also be focused there. Thus, despite observing no statistically significant reduction in stigma in the workplace (see Table 3), a much valuable lesson from the qualitative results indicated that the intervention might have had a spillover effect into the community - thus suggesting the potential to mobilise HCWs as change agents as our findings suggest that they feel confident to convey anti-stigma messages and hold high status in their communities.. This is thus an indication that future research and intervention development for stigma reduction in communities could consider using HCWs as change agents. Regarding interventions in the hospital, the results indicate that future intervention of the kind includes follow-up workshops, where potential challenges can be addressed and the change agents could receive guidance on how to mitigate obstacles. For the healthcare workplace, good relationships between colleagues with less emphasis on hierarchies should be promoted.

\subsection{Limitations}

This study has several limitations. A methodological limitation to the analysis of the trial outcomes was due to the fact that the study was randomised using only eight clusters, four interventions and four control sites. This limited the types of analyses available, but it was still possible to assess the intervention effect through nonparametric tests. However, the design prevented more detailed analyses, such as subgroup analysis. For the feasibility of implementing intervention studies, a relatively small number of clusters can be motivated. We also noted that the measure for TB-REXT was 
not sufficiently reliable, with a Cronbach's $\alpha$ below 0.7 , which should be taken into account when interpreting the results. This could have been because the scale consisted of only three items. Cronbach's $\alpha$ has also been questioned as a test for reliability (Sijtsma, 2009). The scales used to measure HIV- and TB-stigma were developed particularly to measure external stigma directed from HCW to other HCWs, but they sometimes differ from other parts of the literature measuring stigma. This could be a limitation for comparing results to similar studies. Furthermore, we were not allowed to ask about the participants' medical history (if they were HIV-positive or etc.), which would have been useful as control variables for measuring both internal and external stigma and to identify HCWs with personal experience who could be interviewed. Those HCWs could subsequently, with support, have been encouraged to share their own experiences with co-workers and normalise openness. Recent research has shown that knowing an HIV-positive colleague is linked to lowered stigma ( $\mathrm{N}$ Sommerland et al., 2019). They could also participate in the intervention development. Using focus groups seemed to have the drawback that HCWs who knew each other were less forthcoming in their participation and might have been more open in individual anonymous interviews. However, observing the interactions between the participants confirmed that HIV and TB stigma was often a sensitive topic and that constrained relations among co-workers did have a hampering effect on openness around the topic.

\section{Conclusion}

In conclusion, the quantitative combined with the qualitative results describe an intervention that showed potential and might have worked better under different circumstances. Individuals reported new awareness and changed behaviour related to HIV and TB stigma, but a combination of factors seemed to have suppressed the intervention effect. This intervention has generated important lessons and added values for future interventions and focus on reducing stigma in workplace settings. In the qualitative data it became apparent that professional rank, position and social status could intersect with HIV- and TB-stigma. The intervention anticipated this by training hospital staff from all ranks. Addressing different power structures, such as emphasising training of the top management, could be 
beneficial to future interventions. First, change agents need to feel comfortable and confident to perform their task. Secondly, change agents need to be followed up in order to address problems that arise and share promising practices. Finally, the findings further show the potential of using HCWs as change agents to reduce HIV and TB stigma in their local communities rather than in a formally hierarchical setting of the hospital.

\section{ACKNOWLEDGEMENTS}

We are very grateful for the support of the Free State Department of Health: all participant HCWs; hospital chief executive officers (CEOs); members of the Special Committee; and top FSDoH management. We thank the University of Antwerp, and the University of the Free State-particularly the Directorate of Research Development, for their support. We are also most grateful to all fieldworkers: Mosilo Machere, Mampho Machere, Teboho Machere, Seipati Makhoahle, Chris Kaangundue, Maria Montsi, Phumelelo Ngxangane, Bridget Smit, Alfi Moolman and Ryan Mayne. We thank the funder VLIR-OUS.

\section{References}

Adamsi, S., Ehrlichi, R., Ismailii, N., Quaili, Z., \& Jeebhayi, M.F. (2013). Occupational Health Challenges Facing the Department of Health: Protecting employees against tuberculosis and caring for former mineworkers with occupational health disease. In A. Padarath, \& R. English (Eds.), South African Health Review 2012/13 pp. 67-82). Durban: Health Systems Trust.

Baussano, I., Nunn, P., Williams, B., Pivetta, E., Bugiani, M., \& Scano, F. (2011). Tuberculosis among Health Care Workers. Emerg Infect Diseases, 17, 488-494.

Conroy, R.M. (2012). What hypotheses do "nonparametric" two-group tests actually test? Stata Journal, 12, 182-190.

Courtwright, A., \& Turner, A.N. (2010). Tuberculosis and Stigmatization: Pathways and Interventions. Public Health Reports, 125, 34-42.

Daftary, A. (2012). HIV and tuberculosis: The construction and management of double stigma. Social Science \& Medicine, 74, 1512-1519.

de Vries, D.H., Galvin, S., Mhlanga, M., Cindzi, B., \& Dlamini, T. (2011). "Othering" the health worker: self-stigmatization of HIV/AIDS care among health workers in Swaziland. Journal of the International AIDS Society, 14, 60.

Dearing, J.W. (2009). Applying Diffusion of Innovation Theory to Intervention Development. Research on social work practice, 19, 503-518. 
Donnelly, L.R., Bailey, L., Jessani, A., Postnikoff, J., Kerston, P., \& Brondani, M. (2016). Stigma Experiences in Marginalized People Living With HIV Seeking Health Services and Resources in Canada. Journal of the Association of Nurses in AIDS Care, 27, 768-783.

Engelbrecht, M.C., Kigozi, N.G., Chikobvu, P., Botha, S., \& van Rensburg, H.C.J. (2017). Unsuccessful TB treatment outcomes with a focus on HIV co-infected cases: a cross-sectional retrospective record review in a high-burdened province of South Africa. BMC Health Services Research, $17,470$.

Fereday, J., \& Muir-Cochrane, E. (2006). Demonstrating Rigor Using Thematic Analysis: A Hybrid Approach of Inductive and Deductive Coding and Theme Development. International Journal of Qualitative Methods, 5, 80-92.

Fetters, M.D., Curry, L.A., \& Creswell, J.W. (2013). Achieving integration in mixed methods designsprinciples and practices. Health Services Research, 48, 2134-2156.

Feyissa, G.T., Lockwood, C., Woldie, M., \& Munn, Z. (2019). Reducing HIV-related stigma and discrimination in healthcare settings: A systematic review of quantitative evidence. PLOS ONE, 14, e0211298-e0211298.

Goffman, E. (1963). Stigma: Notes on the Management of Spoiled Identity. Engelwood Cliffs: Prentice-Hall.

Hayes, R.J., \& Moulton, L.H. (2009). Cluster Randomised Trials: Taylor \& Francis.

J A Reid, M., Arinaminpathy, N., Bloom, A., R Bloom, B., Boehme, C., Chaisson, R., et al. (2019). Building a tuberculosis-free world: The Lancet Commission on tuberculosis.

Johnson, S.L. (2009). International perspectives on workplace bullying among nurses: a review. International Nursing Review, 56, 34-40.

Joshi, R., Reingold, A.L., Menzies, D., \& Pai, M. (2006). Tuberculosis among Health-Care Workers in Low- and Middle-Income Countries: A Systematic Review. PLoS Medicine, 3, e494.

Khan, R., Yassi, A., Engelbrecht, M.C., Nophale, L., van Rensburg, A.J., \& Spiegel, J. (2015). Barriers to HIV counselling and testing uptake by health workers in three public hospitals in Free State Province, South Africa. AIDS Care, 27, 198-205.

Kinsler, J.J., Wong, M.D., Sayles, J.N., Davis, C., \& Cunningham, W.E. (2007). The effect of perceived stigma from a health care provider on access to care among a low-income HIV-positive population. AIDS Patient Care and STDS, 21, 584-592.

Leech, N.L., \& Onwuegbuzie, A.J. (2009). A typology of mixed methods research designs. Quality \& Quantity, 43, 265-275.

Li, L., Guan, J., Liang, L.-J., Lin, C., \& Wu, Z. (2013a). Popular Opinion Leader Intervention for HIV Stigma Reduction in Health Care Settings. AIDS Education and Prevention, 25, 327-335.

Li, L., Liang, L.-J., Lin, C., Wu, Z., \& Rotheram-Borus, M.J. (2010). HIV prevention intervention to reduce HIV-related stigma: evidence from China. AIDS (London, England), 24, 115-122.

Li, L., Wu, Z., Liang, L.-J., Lin, C., Guan, J., Jia, M., et al. (2013b). Reducing HIV-Related Stigma in Health Care Settings: A Randomized Controlled Trial in China. American Journal of Public Health, 103, 286-292.

Marais, B.J. (2016). The global tuberculosis situation and the inexorable rise of drug-resistant disease. Advanced Drug Delivery Reviews, 102, 3-9.

Nyblade, L., Stangl, A., Weiss, E., \& Ashburn, K. (2009). Combating HIV stigma in health care settings: what works? Journal of the International AIDS Society, 12, 15-15.

Nyblade, L., Stockton, M.A., Giger, K., Bond, V., Ekstrand, M.L., Lean, R.M., et al. (2019). Stigma in health facilities: why it matters and how we can change it. BMC Medicine, 17, 25.

O'Cathain, A., Goode, J., Drabble, S.J., Thomas, K.J., Rudolph, A., \& Hewison, J. (2014). Getting added value from using qualitative research with randomized controlled trials: a qualitative interview study. Trials, 15, 215-215.

O'Cathain, A., Thomas, K.J., Drabble, S.J., Rudolph, A., \& Hewison, J. (2013). What can qualitative research do for randomised controlled trials? A systematic mapping review. BMJ Open, 3, e002889. 
Packard, R.M. (1989). White plague, black labor: Tuberculosis and the political economy of health and disease in South Africa: Univ of California Press.

Quinn, D.M., \& Chaudoir, S.R. (2009). Living with a concealable stigmatized identity: the impact of anticipated stigma, centrality, salience, and cultural stigma on psychological distress and health. Journal of Personality and Social Psychology, 97, 634-651.

Rau, A., Moolman, A., Kigozi, G., Janse van Rensburg, A., Engelbrecht, M., Uebel, K., et al. (2016). Stigma reduction workshops for health care workers in Free State public hospitals: Manual for facilitators. Bloemfontein: Centre for Health Systems Research Development (University of the Free State), Centre for Family, Population and Health (University of Antwerp), Free State Department of Health.

Rau, A., Wouters, E., Engelbrecht, M., Masquillier, C., Uebel, K., Kigozi, G., et al. (2018). Towards a health-enabling working environment - developing and testing interventions to decrease HIV and TB stigma among healthcare workers in the Free State, South Africa: study protocol for a randomised controlled trial. Trials, 19, 351.

Rispel, L. (2016). Analysing the progress and fault lines of health sector transformation in South Africa. South African Health Review, 2016, 17-23.

Rispel, L., \& Bruce, J. (2014). A profession in peril? Revitalising nursing in South Africa. South African Health Review, 2014, 117-125.

Rogers, E.M. (2010). Diffusion of innovations: Simon and Schuster.

Rohleder, P., Swartz, L., Kalichman, S.C., \& Simbayi, L.C. (2009). HIV/AIDS in South Africa 25 Years On: New York: Springer.

Sandelowski, M. (1996). Using qualitative methods in intervention studies. Research in Nursing and Health, 19, 359-364.

Santos, J.R.A. (1999). Cronbach's alpha: A tool for assessing the reliability of scales. Journal of extension, 37, 1-5.

Siegel, J., Yassi, A., Rau, A., Buxton, J.A., Wouters, E., Engelbrecht, M.C., et al. (2015). Workplace interventions to reduce HIV and TB stigma among health care workers - Where do we go from here? Glob Public Health, 10, 995-1007.

Sijtsma, K. (2009). On the Use, the Misuse, and the Very Limited Usefulness of Cronbach's Alpha. Psychometrika, 74, 107-120.

Simbayi, L., Zuma, K., Cloete, A., Jooste, S., Zimela, S., Blose, S., et al. (2015). The people: living with HIV stigma index: South Africa 2014: summary report.

Sommerland, N., Wouters, E., Masquillier, C., Engelbrecht, M., Kigozi, G., Uebel, K., et al. (2017). Stigma as a barrier to the use of occupational health units for tuberculosis services in South Africa. The international journal of tuberculosis and lung disease, 21, S75-S80.

Sommerland, N., Wouters, E., Masquillier, C., Rau, A., Engelbrecht, M., \& Kigozi, G. (2019). Factors Associated With HIV-Related Stigma Toward Colleagues in the Health Care Workforce in South Africa. Journal of the Association of Nurses in AIDS Care, Publish Ahead of Print.

Sontag, S. (1989). IIIness as Metaphor and AIDS and Its Metaphors: Farrar, Straus and Giroux.

South African National AIDS Council. (2017). Let our actions count - South Africa's national strategic plan for HIV, TB and STIs: 2017 - 2022. Pretoria.

Stangl, A.L., Earnshaw, V.A., Logie, C.H., van Brakel, W., C. Simbayi, L., Barré, I., et al. (2019). The Health Stigma and Discrimination Framework: a global, crosscutting framework to inform research, intervention development, and policy on health-related stigmas. BMC Medicine, $17,31$.

Uebel, K.E., Nash, J., \& Avalos, A. (2007). Caring for the Caregivers: Models of HIV/AIDS Care and Treatment Provision for Health Care Workers in Southern Africa. The Journal of Infectious Diseases, 196, S500-S504.

UNAIDS. (2018). Country factsheets South Africa.

Valente, T.W., \& Pumpuang, P. (2007). Identifying Opinion Leaders to Promote Behavior Change. Health Education and Behavior, 34, 881-896. 
van Rensburg, H.C.J., Heunis, J.C., \& Steyn, F. (2012). Human resources for health and health professions in South Africa. In H.C.J. Van Rensburg (Ed.), Health and Healthcare in South Africa pp. 361-431). Pretoria: Van Schaik Publishers.

Wagner, A.C., Hart, T.A., McShane, K.E., Margolese, S., \& Girard, T.A. (2014). Health care provider attitudes and beliefs about people living with HIV: Initial validation of the health care provider HIV/AIDS Stigma Scale (HPASS). AIDS and Behavior, 18.

Waluyo, A., Culbert, G.J., Levy, J., \& Norr, K.F. (2015). Understanding HIV-related Stigma Among Indonesian Nurses. Journal of the Association of Nurses in AIDS Care, 26, 69-80.

Wendt, H.W. (1972). Dealing with a common problem in Social science: A simplified rank-biserial coefficient of correlation based on the U statistic. European Journal of Social Psychology, 2, 463-465.

World Health Organization. (2018). Global tuberculosis report 2018. Geneva.

World Health Organization, International Labour Organization, \& UNAIDS. (2011). The joint WHO-ILOUNAIDS policy guidelines on improving health workers' access to HIV and tuberculosis prevention, treatment, care and support services. Geneva.

Wouters, E., Masquillier, C., Sommerland, N., Engelbrecht, M., Van Rensburg, A., Kigozi, G., et al. (2017). Measuring HIV-and TB-related stigma among health care workers in South Africa: a validation and reliability study. The international journal of tuberculosis and lung disease, 21, S19-S25.

Wouters, E., Rau, A., Engelbrecht, M., Uebel, K., Siegel, J., Masquillier, C., et al. (2016). The Development and Piloting of Parallel Scales Measuring External and Internal HIV and Tuberculosis Stigma Among Healthcare Workers in the Free State Province, South Africa. International Journal of Infectious Diseases, 62, S244-S254. 